\title{
The Meaning of Cardiometabolic Risk in Hypertensive Patients
}

\author{
a report by \\ Luis M Ruilope, ${ }^{1}$ Alejandro de la Sierra, ${ }^{2}$ Julian Segura ${ }^{1}$ and Jose A Garcia-Donaire ${ }^{1}$ \\ 1. Hypertension Unit, 12 de Octubre Hospital, Madrid; 2. Hypertension Unit, Hospital Clinic, Barcelona
}

DOI:10.17925/EE.2007.00.01.51

\begin{abstract}
Cardiometabolic risk is a condition in which the possibilities of developing atherosclerotic cardiovascular (CV) disease and diabetes mellitus are significantly enhanced as a consequence of the presence of insulin resistance and atherogenic dyslipidaemia, the latter being characterised by the presence of low high-density lipoprotein (HDL)-cholesterol and high triglyceride levels.1,2 Cardiometabolic risk is diagnosed by the identification of an enhanced waist circumference (above $102 \mathrm{~cm}$ in males and $88 \mathrm{~cm}$ in females) accompanied by the alterations in lipid profile quoted above (HDL-cholesterol below $40 \mathrm{mg} / \mathrm{dl}$ in males and $50 \mathrm{mg} / \mathrm{dl}$ in females, and serum triglycerides above $150 \mathrm{mg} / \mathrm{dl}$ ).
\end{abstract}

Cardiometabolic risk is particularly prevalent in patients diagnosed as having metabolic syndrome. Correct diagnosis of metabolic syndrome requires - besides an increased waist circumference - low HDL-cholesterol and elevated triglycerides, the potential presence of blood pressure (BP) values above 130/85 $\mathrm{mmHg}$ and a fasting serum glucose above $100 \mathrm{mg} / \mathrm{dl}$ according to a recently revisited Adult Treatment Panel (ATP)-III definition. ${ }^{3,4}$ The International Diabetes Federation (IDF) has similarly defined metabolic syndrome in Europids by the presence of a waist circumference above $94 \mathrm{~cm}$ in males and $80 \mathrm{~cm}$ in females, accompanied by the finding of two out of the other four criteria defined by ATP-III. ${ }^{5}$

How Frequent and Relevant is Cardiometabolic Risk in the Hypertensive Population?

Figure 1 details the prevalence of metabolic syndrome according to ATP$\mathrm{III}^{3}$ and IDF ${ }^{5}$ definitions in a population of more than 1,800 hypertensive patients attending the Hypertension Unit located at the 12 de Octubre Hospital in Madrid, Spain. As can be seen, around $50-70 \%$ of patients were diagnosed as having metabolic syndrome according to the two aforementioned definitions. This figure is not significantly different when a hypertensive population attending primary care settings is considered. ${ }^{6}$

Cardiometabolic risk is, therefore, prevalent in the hypertensive population and, as depicted in Figure 2, needs to be structured into a correct stratification of risk that has to be considered in every hypertensive patient. In fact, the new guidelines of the European Society of Hypertension (ESH) and the European Society of Cardiology (ESC) ${ }^{7}$ consider the concomitant finding of arterial hypertension and metabolic syndrome as a situation of high added CV risk. The reason for this is based on two facts. First, metabolic syndrome and the accompanying cardiometabolic risk result in a significant increase in CV morbidity and mortality in several populationbased studies, as recently reviewed, ${ }^{9}$ as well as in hypertensive patients. ${ }^{10}$ Second, the presence of metabolic syndrome is accompanied by a 3-6-fold increase in the risk of developing type 2 diabetes. ${ }^{11}$

Furthermore, the presence of cardiometabolic risk is accompanied by a significant enhancement in the risk of developing chronic kidney disease, albuminuria and/or a diminished estimated glomerular filtration rate (GFR). The higher the number of criteria satisfied in the diagnosis of metabolic syndrome, the higher will be the prevalence of either microalbuminuria and/or an estimated GFR value $<60 \mathrm{ml} / \mathrm{min} / 1.73 \mathrm{~m}^{2} .^{12}$

\section{How Relevant is the Development of Diabetes}

Mellitus in a Hypertensive Population?

The development of new-onset diabetes and its relevance in hypertensives has been widely considered recently.13,14 The type of antihypertensive therapy used, alone or in combination, affects the acceleration of the appearance of diabetes. A recent network metaanalysis ${ }^{15}$ has shown that the best protection is obtained when angiotensin receptor blockers (ARBs) and converting enzyme inhibitors (CEls) are used, while diuretics and beta-blockers offer the least protection, especially when used in combination.

Although some authors have denied that the development of new-onset diabetes contributes to worsening the short-term (3-5-year) prognosis of hypertensive patients according to the data of studies such as the Systolic Hypertension in the Elderly Program (SHEP) ${ }^{16}$ and the Antihypertensive and Lipid-lowering Treatment to Prevent Heart Attack trial (ALLHAT), ${ }^{17}$ it seems clear that becoming a diabetic must be relevant to the patient's long-term prognosis. In fact, it has been shown that after two and a half years of follow-up beyond that in ALLHAT, the risk of new diabetics was equal to that of patients entering the study as declared diabetics. ${ }^{18}$

\section{How Should a Patient with Hypertension and Cardiometabolic Risk be Treated?}

The aim of intervention in patients with cardiometabolic risk is to achieve an optimal reduction of such risk. Lifestyle modifications counteract the effect of the underlying risk factors (abdominal obesity, physical inactivity and atherogenic diet). Moreover, hypertensives also require a tight BP control, a choice of antihypertensive treatment not producing other metabolic disturbances and, quite often, parallel drug treatment for

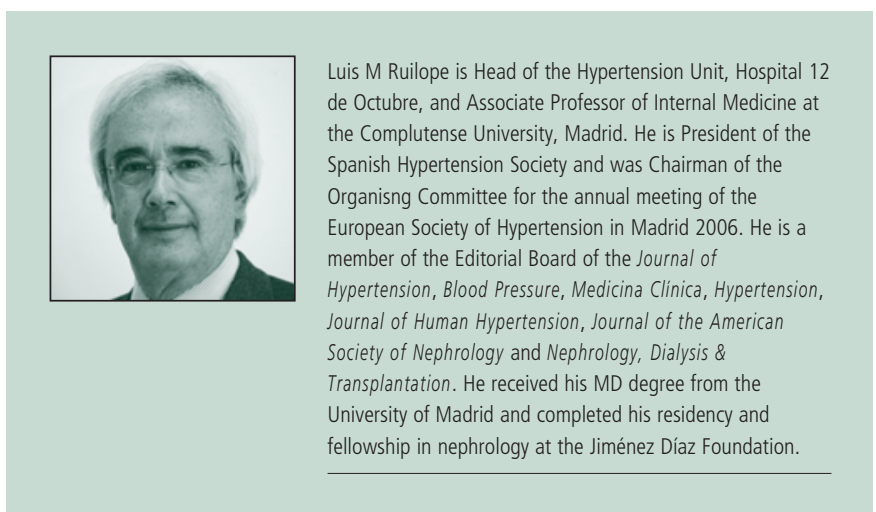




\section{Diabetes \& Cardiovascular Risk}

Figure 1: Prevalence of Metabolic Syndrome in the Hypertensive Population Followed in Our Hypertension Unit Distributed within the Algorithm of Risk Stratification of ESH/ESC Guidelines

\begin{tabular}{|c|c|c|c|c|c|c|}
\hline \multicolumn{7}{|c|}{ Blood Pressure $(\mathrm{mmHg})$} \\
\hline & $\begin{array}{l}\text { Normal } \\
\text { SBS 120-129, } \\
\text { or DBP } 80-84\end{array}$ & $\begin{array}{l}\text { High-normal } \\
\text { SBP 130-139, } \\
\text { or DBP 85-89 }\end{array}$ & $\begin{array}{l}\text { Grade } 1 \\
\text { SBP 140-159, } \\
\text { or DBP 90-99 }\end{array}$ & $\begin{array}{l}\text { Grade 2 } \\
\text { SBP 160-179, or } \\
\text { DBP 100-109 }\end{array}$ & $\begin{array}{l}\text { Grade } 3 \\
S B P \geq 180 \text {, or } \\
D B P \geq 110\end{array}$ & \\
\hline $\begin{array}{l}\text { No other } \\
\text { risk factors }\end{array}$ & $\begin{array}{r}2.9 \\
14.3\end{array}$ & $28 . \overline{0}^{-}$ & $\begin{array}{r}1.8 \\
26.8\end{array}$ & $\begin{array}{r}2.9 \\
37.5\end{array}$ & 42.9 & $\begin{array}{r}2.7 \\
26.5\end{array}$ \\
\hline $\begin{array}{l}1-2 \\
\text { risk factors }\end{array}$ & $\begin{array}{l}41.3 \\
59.8\end{array}$ & $\begin{array}{l}33.0 \\
58.3\end{array}$ & $\begin{array}{l}32.3 \\
57.3\end{array}$ & $\begin{array}{l}40.7 \\
62.8\end{array}$ & $\begin{array}{l}40.7 \\
55.9\end{array}$ & $\begin{array}{l}36.2 \\
58.8\end{array}$ \\
\hline $\begin{array}{l}3 \text { or more risk } \\
\text { factors, target } \\
\text { organ damages } \\
\text { metabolic } \\
\text { syndrome or } \\
\text { diabetes }\end{array}$ & es & $\begin{array}{l}67.0 \\
75.2\end{array}$ & $\begin{array}{c}67.4 \\
79.4\end{array}$ & $\begin{array}{l}69.2 \\
84.9\end{array}$ & $\begin{array}{l}69.3 \\
84.3\end{array}$ & $\begin{array}{l}66.9 \\
80.9\end{array}$ \\
\hline $\begin{array}{l}\text { Associated } \\
\text { clinical } \\
\text { conditions }\end{array}$ & $\begin{array}{l}40.0 \\
51.1\end{array}$ & $\begin{array}{l}53.3 \\
73.3\end{array}$ & $\begin{array}{l}59.5 \\
74.1\end{array}$ & $\begin{array}{l}67.6 \\
81.1\end{array}$ & $\begin{array}{l}69.0 \\
76.2\end{array}$ & $\begin{array}{l}58.8 \\
72.7\end{array}$ \\
\hline & $\begin{array}{l}39.9 \\
57.7\end{array}$ & $\begin{array}{l}46.3 \\
64.7\end{array}$ & $\begin{array}{l}48.4 \\
66.5\end{array}$ & $\begin{array}{l}57.1 \\
75.0\end{array}$ & $\begin{array}{l}60.0 \\
74.5\end{array}$ & $\begin{array}{l}50.2 \\
67.8\end{array}$ \\
\hline
\end{tabular}

Figures are percentages: ATP-III (figures in italics) and IDF (figures in bold).

associated metabolic risk factors (dyslipidaemia, insulin resistance and prothrombotic and proinflammatory states).

\section{Lifestyle Interventions}

Lifestyle interventions are the first step in achieving cardiometabolic risk reduction. The key lifestyle interventions are the promotion of exercise and energy expenditure and the reduction of overweight by caloric restriction. ${ }^{19}$ The minimal requirements for long-term effectiveness include caloric restriction in the range of 500-1,000kcal with $7-10 \%$ weight loss in 12 months and regular aerobic exercise of 30-45 minutes daily. Whereas extreme caloric-restricted or elementdissociated diets have no long-term advantages, more intensive exercise programmes have additional $C V$ benefits and help to maintain weight loss. Lifestyle interventions have beneficial effects on BP and the lipid profile and reduce the incidence of new-onset diabetes. ${ }^{20}$ Moreover, recent data suggest a long-term effect on the reduction in CV morbidity. ${ }^{21}$

Other lifestyle changes also have a beneficial effect on specific CV risk factors and must be encouraged in specific patients. Lowering salt intake and alcohol consumption have moderate BP-lowering effects, which are enhanced in conjunction with weight loss and increased exercise. ${ }^{7}$ In addition, a diet rich in fruit, vegetables and low-fat dairy products - dietary approaches to stop hypertension (DASH) diet - substantially lowers BP in comparison with the standard American diet.22 Finally, the Mediterranean diet, which is also rich in fruit, vegetables, fish and olive oil, has a favourable impact on atherogenic dyslipidaemia in metabolic syndrome patients. ${ }^{23}$

Maintenance of lifestyle changes requires counselling and may prove difficult in the long term. For this reason, pharmacological treatment of $\mathrm{BP}$, dyslipidaemia, insulin resistance and obesity will be required for most patients to reduce cardiometabolic risk.

\section{Antihypertensive Therapy}

As mentioned above, the new ESH/ESC guidelines ${ }^{7}$ emphasise the importance of metabolic syndrome as an indicator of high added CV risk in hypertensives, thus indicating early antihypertensive treatment if lifestyle measures are not enough to reach BP targets.

No comparative studies of the different antihypertensive drug classes in hypertensives with metabolic syndrome are available. However, the choice of antihypertensive treatment must take the increased risk of developing new-onset diabetes in these subjects into account. Some international guidelines recommend diuretics as the first-step therapy for hypertensive patients without a compelling indication for other antihypertensive drug classes. However, it has been established that diuretics increase the risk of new-onset diabetes compared with placebo (23\% increase for diuretics). ${ }^{15}$ Conversely, calcium channel blockers and, especially, renin-angiotensin system (RAS) blockers - angiotensin receptor blockers (ARBs) and angiotensin-converting-enzyme (ACE) inhibitors decrease this risk (33\% decrease with ACE inhibitors and $43 \%$ decrease with ARBs). These differences are probably even more pronounced in the specific subset of patients with metabolic syndrome and high cardiometabolic risk. Thus, it seems reasonable that the first consideration in antihypertensive treatment in hypertensives with high cardiometabolic risk should be the inhibition of the RAS with either ACE inhibition or angiotensin blockade.

There is no evidence to support a preference for one or the other of these two forms of RAS blockade. Some of the ARBs seem to have specific metabolic actions, such as partial agonism of the nuclear receptor peroxisome proliferator-activated receptor (PPAR)-gamma, although this has not yet been translated into a proven clinical benefit.

Non-hypertensive patients with metabolic syndrome usually have highnormal BP (systolic 130-139mmHg and/or diastolic $85-89 \mathrm{mmHg}$ ). Specific dietary interventions, such as sodium restriction or the adoption of the DASH diet, in addition to caloric restriction and increased exercise, could be helpful. For patients also having diabetes or chronic kidney disease, antihypertensive therapy is mandatory. ${ }^{7}$ For the remaining

...the new ESH/ESC guidelines ${ }^{7}$

emphasise the importance of metabolic syndrome as an indicator of high added cardiovascular risk in hypertensives, thus indicating early antihypertensive treatment if lifestyle measures are not enough to reach blood pressure targets.

subjects, there is no consensus on whether antihypertensive treatment is recommendable when lifestyle measures are not effective.

Various evidence can help to guide this decision. First, the Framingham Study ${ }^{24}$ found that subjects with high-normal BP were at increased risk of CV events compared with those with optimal BP (less than 120/80 $\mathrm{mmHg}$ ). Second, the rate of developing hypertension in a short period (three years) for those with BP higher than 120/80 $\mathrm{mmHg}$ has been reported as very high (40\% in subjects older than 64 with BP higher than $130 / 85 \mathrm{mmHg}$ ). ${ }^{25}$ In the same way, the recent Trial of Preventing Hypertension (TROPHY) found 
that, over a period of four years, stage 1 hypertension developed in nearly two-thirds of patients with untreated prehypertension (values of 120-139 and/or $80-89 \mathrm{mmHg}$ ), and that antihypertensive treatment reduced the risk of incident hypertension in these patients. ${ }^{26}$

On the basis of these considerations, it can be hypothesised that antihypertensive treatment could be of benefit for subjects with highnormal BP and high cardiometabolic risk. However, a clear indication needs to be based on a prospective interventional study showing decreased mortality and/or morbidity.

\section{Lipid-lowering Therapy}

For hypertensives with cardiometabolic risk but without diabetes or CV disease, the evidence is scarce. However, the Anglo-Scandinavian Cardiac Outcomes Trial (ASCOT) demonstrated that treatment with $10 \mathrm{mg}$ atorvastatin was effective in reducing $\mathrm{CV}$ events when hypertension was accompanied by three or more additional risk factors, including most that are contained in the definition of metabolic syndrome. ${ }^{29}$

The typical dyslipidaemia in hypertensives with cardiometabolic risk is characterised by low HDL-cholesterol and increased triglycerides. Two classes of drugs reduce triglycerides and increase HDL-cholesterol: nicotinic acid and fibrates. Although limited evidence is available, some post-hoc analyses suggest a beneficial effect of these drugs in patients with metabolic syndrome, insulin resistance or diabetes. ${ }^{30-33}$ Thus, current evidence recommends the use of fibrates or nicotinic acid in hypertensive patients with metabolic syndrome and hypertriglyceridaemia, but these agents should be used with caution in those receiving concomitant statin treatment, especially at higher doses, due to the increased risk of myopathy and liver disorders. Finally, other apparently promising alternatives, such as cholesteryl ester transfer protein (CETP) inhibition have recently been associated with increased mortality. ${ }^{34}$

\section{Insulin Sensitisers}

In addition to lifestyle changes, treatment with metformin, ${ }^{20}$ acarbose ${ }^{35}$ and thiazolidindiones ${ }^{36}$ decreases the risk of new-onset diabetes in patients with impaired glucose tolerance. However, the long-term benefits of these drugs and the cost-benefit analysis have not been adequately addressed. In fact, a recent meta-analysis suggests a deleterious effect of rosiglitazone on cardiac outcomes. ${ }^{37}$

\section{Antiobesity Drugs}

Abdominal obesity is one the main components of cardiometabolic risk. In addition to a restricted caloric diet and increased exercise, three different pharmacological approaches are available for weight loss. Sibutramine is the only drug affecting monoaminergic systems currently approved for the long-term control of obesity. Several clinical trials have demonstrated the superiority of sibutramine with respect to placebo in reducing weight and waist circumference (median at one year: $4.5 \mathrm{~kg}$ ). In hypertensives, sibutramine slightly increases BP and heart rate and should be used with caution. ${ }^{38}$ However, a recent trial suggests that the effects of sibutramine in hypertensives under antihypertensive treatment largely depend on the type of antihypertensive drug used. ${ }^{39}$ Thus, sibutramine - when coadministered with a combination of RAS blockers and calcium channel blockers - does not interfere with the antihypertensive effect of such a combination.
Figure 2: Global Cardiometabolic Risk Includes the Presence of Metabolic Syndrome and Traditional Cardiovascular Risk Factors

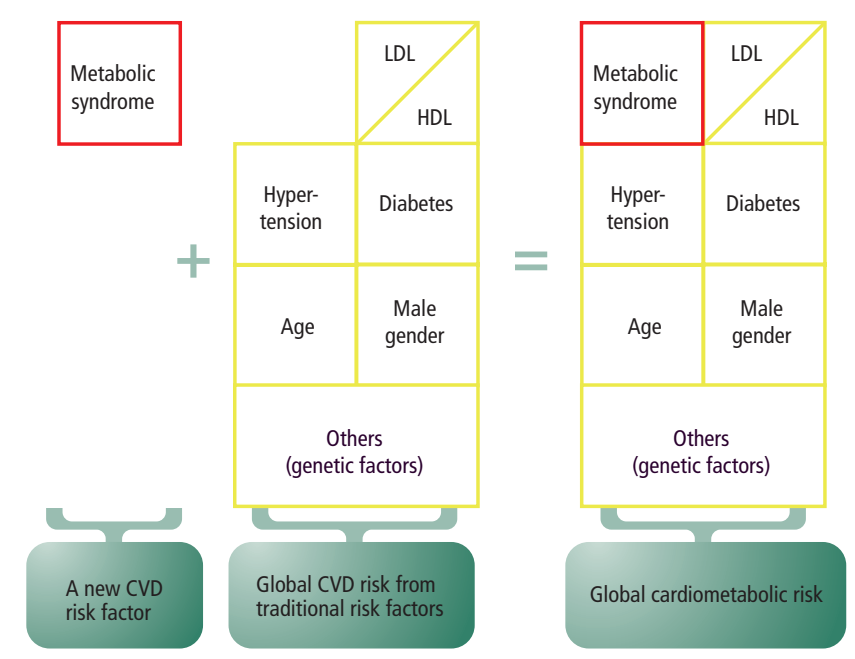

Orlistat is an inhibitor of gastrointestinal lipases, especially pancreatic lipase. Its efficacy in producing a superior weight loss with respect to placebo has also been proven, although the weight loss is usually less than that obtained with sibutramine. Orlistat has a favourable influence on lipids and glycaemic control, especially in diabetics, although gastrointestinal tolerance is poor. ${ }^{40}$

Rimonabant is the first antagonist of the endocannabinoid (CB1) receptor. The Rimonabant In Obesity (RIO) programme has demonstrated a significant effect of this drug on long-term weight reduction in overweight patients with additional $\mathrm{CV}$ risk factors at one year, ${ }^{41}$ maintained at two years, ${ }^{42}$ in hyperlipidaemic overweight subjects ${ }^{43}$ and in type 2 diabetics. ${ }^{44}$ In all these trials, the beneficial effects on HDL-cholesterol and triglycerides, and on glycated haemoglobin in diabetics, exceeded those expected due to weight loss.

These facts have led to the consideration that Rimonabant is a drug primarily directed to $\mathrm{CV}$ protection through a direct reduction of the components of cardiometabolic risk. Studies of the effect of this CB1 receptor antagonist on $\mathrm{CV}$ outcomes in patients at risk are ongoing.

\section{Antithrombotic Drugs}

A key feature of metabolic syndrome that explains the increased cardiometabolic risk is an enhanced pro-thrombotic state, especially in the presence of insulin resistance. Postprandial hyperglycaemia, increased free fatty acids and elevated triglyceride levels may all have adverse effects on platelets, coagulation and fibrinolysis. Pharmacological interventions targeting these abnormalities have the potential to reduce thrombosis. Antiplatelet drugs such as low-dose aspirin or clopidogrel represent an option in the management of hypertensives with cardiometabolic risk. The benefit is probably higher in type 2 diabetics ${ }^{45}$ and conclusive in those with previous CV disease. ${ }^{46}$ Efforts to control BP should be reinforced before the introduction of aspirin.

\section{Anti-inflammatory Drugs}

Insulin resistance is now recognised as an inflammatory disease, with 
levels of inflammatory markers such as C-reactive protein, plasminogen activator inhibitor (PAI)-1 and interleukin (IL)- 6 being present in higher concentrations in insulin-resistant individuals than in healthy counterparts. ${ }^{47} \mathrm{C}$-reactive protein is increasingly regarded as a useful measure of CV risk. ${ }^{48}$ Aspirin, statins and - to a lesser extent RAS inhibitors, reduce the inflammatory process and prevent $C V$ disease. Vitamins or other specific anti-inflammatory drugs are not usually recommended.

\section{Closing Remarks}

Although there are several areas of uncertainty with respect to the definition, usefulness and pathogenesis of metabolic syndrome, simple clinical tools exist that identify subjects at a higher risk of developing both type 2 diabetes and CV disease, and thus having high cardiometabolic risk. The management of these subjects is based principally on lifestyle measures, but various antihypertensive, lipidlowering, insulin-sensitising, antiobesity and antiplatelet drugs could be helpful in reducing the cardiometabolic risk.

Population-based strategies are necessary to reduce the impact of underlying risk factors for cardiometabolic risk (obesity, physical inactivity and atherogenic diet). Although evidence is scarce, there is general agreement that more aggressive therapy is required to reduce the risk of new diabetes and CV disease further. Prospective, randomised trials addressing the effect of potentially beneficial treatments on cardiometabolic outcomes should be strongly encouraged.
1. Eckel RH, Kahn R, Robertson RM, Rizza RA, Preventing cardiovascular disease and diabetes, Diabetes Care, 2006;29:1697-99

2. Despres JP, Lemieux I, Abdominal obesity and metabolic syndrome, Nature, 2006;444:881-7.

3. Third report of the National Cholesterol Education Program (NCEP) expert panel on detection, evaluation, and treatment of high blood cholesterol in adults (Adult Treatment Panel III): Final report, Circulation, 2002:106:3143-3421.

4. Grundy SM, Cleeman Jl, Daniels SR, et al., Diagnosis and management of the metabolic syndrome: An American Heart Association/National Heart, Lung, and Blood Institute Scientific Statement, Circulation, 2005;112:2735-52.

5. Alberti KG, Zimmet P, Shaw J, Metabolic syndrome: a new worldwide definition: A Consensus Statement from the International Diabetes Federation, Diabet Med, 2006;23:469-80.

6. De la Sierra A, Romero R, Bonet J, Prevalence and genera features of the metabolic syndrome in the Spanish hypertensive population, Med Clin (Barc), 2006;126:406-9.

7. The Task Force for the Management of Arterial Hypertension of the European Society of Hypertension (ESH) and of the European Society of Cardiology (ESC) Guidelines for the Management of Arterial Hypertension, I Hypertens, in press.

8. Lakka HM, Laaksonen DE, Lakka TA, et al., The metabolic syndrome and total and cardiovascular disease mortality in middle-aged men, JAMA, 2002;288:2709-16.

9. Galassi A, Reynolds K, He J, Metabolic syndrome and risk of cardiovascular disease: a meta-analysis, Am J Med, 2006;119:812-19.

10. Schillaci G, Pirro M, Vaudo G, et al., Prognostic value of the metabolic syndrome in essential hypertension, I Am Coll Cardiol, 2004;43:1817-22.

11. Ford ES, Risks for all-cause mortality, cardiovascular disease, and diabetes associated with the metabolic syndrome: a summary of the evidence, Diabetes Care, 2005;28:1769-78.

12. Kurella M, Lo JC, Chertow GM, Metabolic syndrome and the risk for chronic kidney disease among nondiabetic adults, J Am Soc Nephrol, 2005; 16:2134-40.

13. Samuelsson O, Pennert K, Andersson O, et al., Diabetes mellitus and raised serum triglyceride concentration in treated hypertension: are they of prognostic importance? Observational study, BMJ, 1996;314:660-63.

14. Verdecchia P, Reboldi $G$, Angeli F, et al., Adverse prognostic significance of new diabetes in treated hypertensive subjects, Hypertension, 2004;43:963-9.

15. Elliott WJ, Meyer PM, Incident diabetes in clinical trials of antihypertensive drugs: a network meta-analysis, Lancet, 2007;369:201-7.

16. Kostis JB, Wilson AC, Freudenberger RS, et al., and the SHEP Collaborative Research Group, Long-term effect of diureticbased therapy on fatal outcomes in subjects with isolated systolic hypertension with and without diabetes, Am J Cardiol, 2005;95:29-35.

17. Barzilay Jl, Davis BR, Cutler JA, et al., Fasting glucose levels and incident diabetes mellitus in older nondiabetic adults randomized to receive 3 different classes of antihypertensive treatment: a report from the Antihypertensive and LipidLowering Treatment to Prevent Heart Attack Trial (ALLHAT), Arch Intern Med, 2006;166:2191-2201.
18. Alderman MH, Cohen H, Madhavan S, Diabetes and cardiovascular events in hypertensive patients, Hypertension, 1999;33:1130-34

19. Klein $S$, Burke $L E$, Bray $G A$, et al., Clinical implications of obesity with specific focus on cardiovascular disease: a statement for professionals from the American Heart Association Council on Nutrition, Physical Activity, and Metabolism: endorsed by the American College of Cardiology Foundation, Circulation, 2004:110:2952-67.

20. Knowler WC, Barrett-Connor E, Fowler SE, et al., Reduction in the incidence of type 2 diabetes with lifestyle intervention or metformin, N Engl J Med, 2002;346:393-403.

21. Cook NR, Cutler JA, Obarzanek E, et al., Long term effects of dietary sodium reduction on cardiovascular disease outcomes: observational follow-up of the trials of hypertension prevention (TOHP), BMJ, 2007;334:885.

22. Sacks FM, Svetkey LP, Vollmer WM, et al., Effects on blood pressure of reduced dietary sodium and the Dietary Approaches to Stop Hypertension (DASH) diet. DASH-Sodium Collaborative Research Group, N Engl I Med, 2001;344:3-10.

23. Knoops KT, de Groot LC, Kromhout D, et al., Mediterranean diet, lifestyle factors, and 10-year mortality in elderly European men and women: the HALE project, JAMA, 2004;292:1433-9.

24. Vasan RS, Larson MG, Leip EP, et al., Impact of high-normal blood pressure on the risk of cardiovascular disease, N Engl J Med, 2001;345:1291-7.

25. Vasan RS, Larson MG, Leip EP, et al., Assessment of frequency of progression to hypertension in non-hypertensive participants in the Framingham Heart Study: a cohort study, Lancet, 2001;358:1682-6

26. Julius $S$, Nesbitt SD, Egan BM, et al., Feasibility of treating prehypertension with an angiotensin-receptor blocker, $N$ Engl Med, 2006;354:1685-97.

27. Colhoun HM, Betteridge DJ, Durrington PN, et al., Primary prevention of cardiovascular disease with atorvastatin in type 2 diabetes in the Collaborative Atorvastatin Diabetes Study (CARDS): multicentre randomised placebo-controlled trial, Lancet, 2004;364:685-96.

28. Heart Protection Study Collaborative Group. MRC/BHF Heart Protection Study of cholesterol lowering with simvastatin in 20,536 high-risk individuals: a randomised placebo-controlled trial, Lancet, 2002;360:7-22.

29. Sever PS, Dahlof $B$, Poulter NR, et al., Prevention of coronary and stroke events with atorvastatin in hypertensive patients who have average or lower-than-average cholestero concentrations, in the Anglo-Scandinavian Cardiac Outcomes Trial_Lipid Lowering Arm (ASCOT-LLA): a multicentre randomised controlled trial, Lancet, 2003:361:1149-58.

30. Canner PL, Furberg CD, McGovern ME, Benefits of niacin in patients with versus without the metabolic syndrome and healed myocardial infarction (from the Coronary Drug Project), Am J Cardiol, 2006;97:477-9.

31. Rubins HB, Robins SJ, Collins D, et al., Diabetes, plasma insulin and cardiovascular disease: subgroup analysis from the Department of Veterans Affairs High-density lipoprotein Intervention Trial (VA-HIT), Arch Intern Med 2002;162:2597-2604.

32. Tenenbaum A, Motro M, Fisman EZ, et al., Bezafibrate for the secondary prevention of myocardial infarction in patients with metabolic syndrome, Arch Intern Med, 2005;165:1154-60.
33. Keech $A$, Simes RJ, Barter $P$, et al. Effects of long-term fenofibrate therapy on cardiovascular events in 9795 people with type 2 diabetes mellitus (the FIELD study): randomised controlled trial. Effects of long-term fenofibrate therapy on cardiovascular events in 9795 people with type 2 diabetes mellitus (the FIELD study): randomised controlled trial, Lancet, 2005;366:1849-61.

34. Nissen SE, Tardif JC, Nicholls SJ, et al., Effect of torcetrapib on the progression of coronary atherosclerosis, N Engl J Med, 2007;356:1304-16.

35. Chiasson JL, Josse RG, Gomis R, et al., Acarbose for prevention of type 2 diabetes mellitus: the STOP-NIDDM randomised trial, Lancet, 2002;359:2072-7.

36. The DREAM (Diabetes Reduction Assessment with ramipril and rosiglitazone Medication) Trial Investigators. Effect of rosiglitazone on the frequency of diabetes in patients with impaired glucose tolerance or impaired fasting glucose: a randomised controlled trial, Lancet, 2006;368:1096-1105.

37. Nissen SE, Wolski K, Effect of rosiglitazone on the risk of myocardial infarction and death from cardiovascular causes, N Engl J Med, 2007; Epub ahead of print.

38. Arterburn DE, Crane PK, Veenstra DL, The efficacy and safety of sibutramine for weight loss: a systematic review, Arch Intern Med, 2004;164:994-1003.

39. Scholze J, Grimm E, Hermann D, et al., Optimal treatment of obesity-related hypertension: the Hypertension-ObesitySibutramine (HOS) study, Circulation, 2007;115:1991-8.

40. Hutton B, Fergusson D, Changes in body weight and serum lipid profile in obese patients treated with orlistat in addition to a hypocaloric diet: a systematic review of randomized clinical trials, Am J Clin Nutr, 2004;80:1461-8.

41. Van Gaal LF, Rissanen AM, Scheen AJ, Effects of the cannabinoid-1 receptor blocker rimonabant on weight reduction and cardiovascular risk factors in overweight patients: 1-year experience from the RIO-Europe study, Lancet, 2005;365: 1389-97.

42. Pi-Sunyer $\mathrm{FX}$, Aronne LJ, Heshmati HM, Effect of rimonabant, a cannabinoid-1 receptor blocker, on weight and cardiometabolic risk factors in overweight or obese patients: RIO-North America: a randomized controlled trial, JAMA, 2006;295:761-75.

43. Despres JP, Golay A, Sjostrom L, Effects of rimonabant on metabolic risk factors in overweight patients with dyslipidemia, N Engl J Med, 2005;353:2121-34.

44. Scheen AJ, Finer N, Hollander P, et al., Efficacy and tolerability of rimonabant in overweight or obese patients with type 2 diabetes: a randomised controlled study, Lancet, 2006;368: 1660-72.

45. Gaede $P$, Vedel $P$, Larsen N, et al., Multifactorial intervention and cardiovascular disease in patients with type 2 diabetes, N Engl J Med, 2003;348:383-93.

46. Antithrombotic Trialists' Collaboration. Collaborative metaanalysis of randomised trials of antiplatelet therapy for prevention of death, myocardial infarction, and stroke in high risk patients, BMJ, 2002;324:71-86.

47. Garg R, Tripathy D, Dandona P, Insulin resistance as a proinflammatory state: mechanisms, mediators, and therapeutic interventions, Curr Drug Targets, 2003;4:487-492.

48. Lloyd-Jones DM, Liu K, Tian L, Greenland P, Narrative review: Assessment of $\mathrm{C}$-reactive protein in risk prediction for cardiovascular disease, Ann Intern Med, 2006;145:35-42. 